\title{
Small misunderstandings among us animals
}

\author{
Review of the book by Lisa Vozza \& Giorgio Vallortigara
}

\author{
A Vitale ${ }^{1}$ \\ ${ }^{1}$ Center for Behavioural Sciences and Mental Health. Istituto Superiore di Sanità.
}

submitted: Jun 7, 2019, accepted: Jun 7, 2019, EPub Ahead of Print: Jun 13, 2019

Conflict of interest: None

DOI: 10.24019/jtavr.63 - Corresponding author: Augusto Vitale, augusto.vitale@iss.it

(C) 2018 Fondazione Vasculab impresa sociale ONLUS. All rights reserved.

When I was in Scotland for my $\mathrm{PhD}$ course, my supervisor told me once that what was interesting in comparative ecology and ethology was not the differences among different species, but the similarities. Similarities were more interesting, because they would potentially shed some light on significant evolutionary mechanisms. He was obviously right but differences, although perhaps more expected and less challenging, can be source of great interest and fascination too. One of my main interests is the behavior of non-human primates. Most of the times, when I am interviewed, the classical question "how similar are monkeys to us?" comes up sooner or later. It seems that we have this urge to understand other animals in terms of similarities/differences with us, humans, the supreme meter of zoological comparison (some could say: "and what other paradigm could we use?"). Are they intelligent like us? Do they feel like us? Do they suffer like us?

Obviously, the answers to these questions, even if some of us would consider them just inappropriate, are related to the knowledge we have of the other species with which we share (and sometime destroy) the planet we live in. And what we know about the other animals? Do we understand why they are doing what they are doing? Therefore, the question of similarity versus difference between us and the other animals is an old one. However, it still maintains all of its fascination and relevance, because it sits at very heart of what we understand as evolutionary process in Darwinian terms. And it is not all. It also concerns the way we see animals, the way we describe them and the way we interact with them.
The issues of what distinguish us from other animals, but more what we really know about them, are central points, among others, of this little and agile book written by Lisa Vozza and Giorgio Vallortigara ${ }^{1}$. The two authors are well known, both in their respective professional environment, being Vozza the Scientific Officer of the Italian Association for Research on Cancer, and Vallortigara a well-known and very respected neuroscientist. Furthermore, they are both authors of popular books which explain in simple and clear terms scientific topics to the general public. The present book is no exception. The continuum between the humans and the other animals is illustrated with a series of little delicious scenarios, which range from the ability to count of chimpanzees to the incredible spatial memory of the scrub jays.

To discuss how we relate to the other animals one of the starting points is anthropomorphism, the tendency to provide animals with feelings and motivations typical of us humans (it is a tendency that dogs' owners, like me, sometimes find incredibly difficult to resist, I must admit...). The authors, although they warn us against the comfort anthropomorphism offers us in making us believe that we do understand other animals' motivations, do not completely deny its possible value. As matter of fact, anthropomorphism suggests interpretations of animal behavior that can be verified with controlled experiments. In my personal experience, to attribute human emotions and feelings to non-human animals can be a way to identify real problems related to the welfare of animals close to us. This 
is particularly true for dedicated and empathic technicians working with captive animals in research laboratories.

But the one of the main points of the authors is also to give the lie to some of the beliefs we have about other animals. The cover of the book already offers a good example. The sweet koala tenderly embracing the trunk of a tree appear to us like a fluffy and irresistible lazy animal; not really: the temperature of its environment is very high, Koalas cannot sweat, so they needs to embrace a tree which helps them to cool down.

The book is organized in a series of brief and readerfriendly chapters, each one dedicated to a particular theme, mainly related to animal behavior, and for each topic there is a list of suggested readings. Through the ten chapters, a series of false beliefs about animals are revealed and clarified, with the help of researchers who have approached a particular ethological question. There is also no shame in saying that certain aspects of other animals' lives are just still mysterious to us. Do we really have a way to describe what intelligence is for a species different from ours, for example? I do agree with what Vallortigara and Vozza say in this respect: all of the animals are intelligent, and their intelligence is strictly related to the ecological and social environment in which they have evolved and developed. The same goes for other characteristics, such as vision and other physical and cognitive skills. In this argument we can find the idea that evolution is not directional, does not have an aim to go from less complex to more complex, that complexity is of relative importance in term of evolution and that, surely, we humans are not on the top of an hypothetical evolutionary pyramid.

What about conscience? This is really a slippery topic. I am very tempted to agree with a quotation the two authors use to discuss the nature of conscience: "It is something us humans invented to feel important". The literature about conscience in non-human species is as vast as heterogeneous, and it reflects the fact that it is nearly impossible to measure in a scientific and objective way something that is very personal and subjective. We have difficulties in talking about conscience among ourselves, who can directly express what we feel? Can we imagine asking a bat? I agree with the authors' claim that the moral relevance of a particular animal has very little to do with its cognitive abilities. This leads me to say that the respect for the other animals must not depend on their "intelligence" (whatever that means...), and looking for similarities with humans is not the way to attribute a particular moral status to a particular animal.

The last chapter is dedicated to an issue very close to my heart, that is, the use of animals in biomedical and toxicological experiments. The authors' approach to the issue in a very sensitive way, especially in the case of Vallortigara's experience. To scream against or in favor of animal experiments does not help to understand the complexity of this practice and, surely, does not help the animals that are still used in research laboratories. The authors are very honest in claiming that they simply don't know if it is right or wrong to use animals for research, and suggest finding an acceptable shade of grey. I agree and have no reason to doubt the truthfulness of the argument "I would prefer doing it another way", and I also agree with the affirmation that the evolution of the norms protecting the animals used in research laboratories has to do with the pressure exercised by animal lovers. I think that the author's approach set an example to be followed. There is a need for the scientific community to speak out about their research using animal models. What are their motivations? How do they solve the ethical problems related to animal experimentation? Openness of this kind can really improve the discussion about animal experiments, discussion which suffers in a chronic way of poor theoretical argumentation from both sides.

\section{Lisa Vozza Giorgio Vallortigara Piccoli equivoci tra noi animali}

Siamo sicuri di capirci con le altre specie?

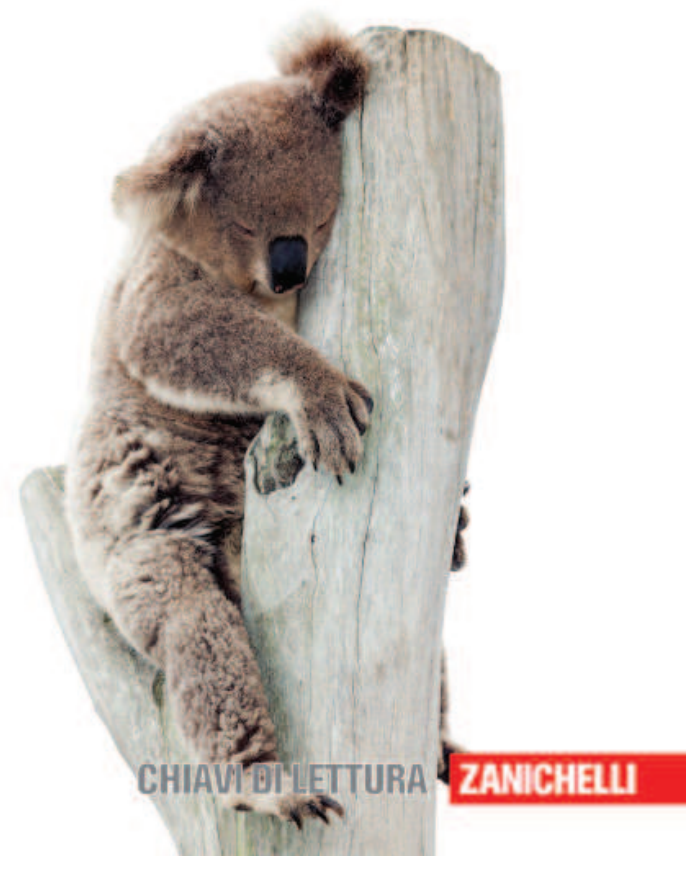

Small misunderstandings among us animals, by Lisa Vozza \& Giorgio Vallortigara. 
Another point I am personally fascinated with is the different treatment we reserve to the same animal, depending on the context. I always thought that, in a way or another, we "create" the animals we deal with: we do not really understand the other animals, we have a vague idea of what they think and what they feel. Therefore, it is very appropriate the choice to illustrate, towards the end of the book, five different scenarios with the ferrets as protagonists. In one case, for example, a ferret is welcome in a house, adopted as a pet, given a name. In another case, the ferret has found a place to stay in the space between the last floor and the roof of a house: the owners will use any possible way (traps, poisons...) to get rid of the animal, with little concern for its welfare. Something completely different happens in a research laboratory, where the ferret is used as a model to better understand how to prevent and cure an infectious disease. In this case the animals are eliminated at the end of the study (although not always), but before reaching that point, they are treated with the most possible respect for their well-being, following the indications of European and local norms and animal experimentation. Completely different situations, but the species is exactly the same. It suggests that our relationship with other species is very ambiguous indeed.

This book can easily be an interesting and stimulating companion, to be read all at once in few hours, or to be enjoyed reading a chapter here and there, as each one of them can stand on its own, and little summaries of the main points are provided. At the very end we can find two very useful sections: " 13 false beliefs on animals", and "Probably you did not know...". Here the study of animal behaviour does not want to spoil the bond we think we can create with the other animals, finding aseptic scientific explanations of their behaviours, Instead it is just the opposite: a more objective approach, looking for mechanisms, applying the Occam's razor (consider first the simpler explanations for a particular behavioural phenomenon), can help us to discover real wonders of the other species' variability and ethological richness. Re-think the false beliefs with the help of a bit of science does not have to a defeat for the love and respect we have for the other animals.

The message I get from this reader-friendly book, is that both differences and similarities are relevant for the consideration we must have of the other species. Similarities can make us smile and feel closer to the other species, especially when we can detect similarities in emotions. However, differences are a source of surprise and admiration for something different from us, and the respect for differences is the name of the game.

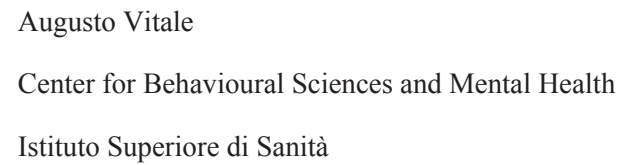

\section{References}

1) Vozza L, Vallortigara G. Piccoli equivoci tra noi animali [Small misunderstandings among us animals]. Zanichelli Ed., Bologna, 2015. 